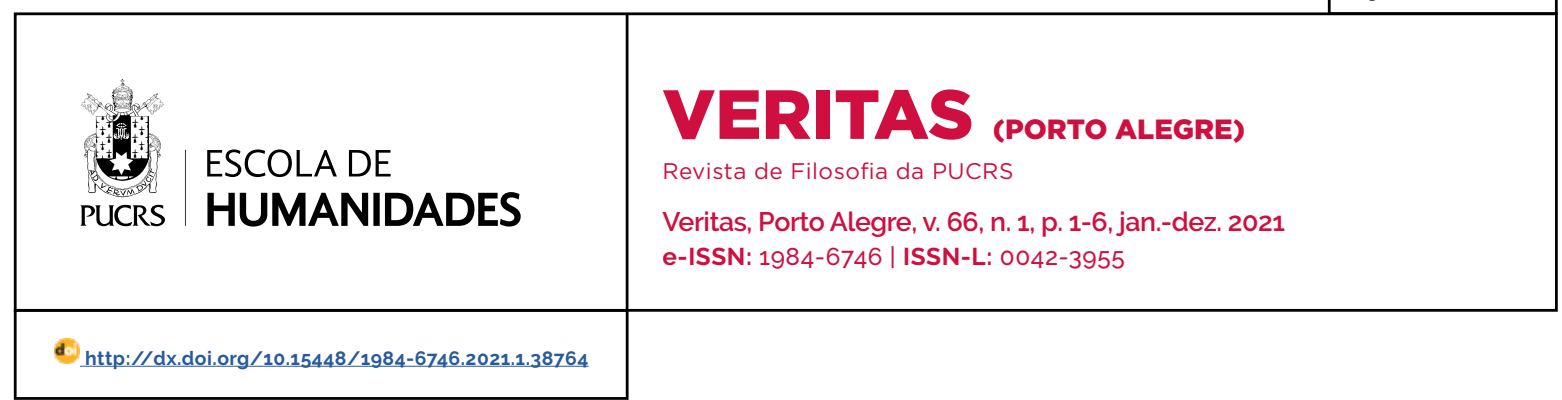

RESENHA

\title{
Reflexões filosóficas sobre a história: Agostinho, Hegel e Nietzsche
}

Philosophical reflections on history: Augustine, Hegel and Nietzsche

Reflexiones filosóficas sobre la historia: Agustin. Hegel y Nietzsche

Roberto Barros ${ }^{1}$

orcid.org/0000-0001-6142-450X

robertbarr@ufpa.br

Recebido em: 5 ago. 2020.

Aprovado em: 17 ago. 2020.

Publicado em: 3 nov. 2021.

\section{(c) (i)}

Artigo está licenciado sob forma de uma licença Creative Commons Atribuição 4.0 Internacional.
JULIÃO, José Nicolao. Reflexões filosóficas sobre a história: Agostinho, Hegel e Nietzsche. Rio de Janeiro: Ed. ViaVerita, 2019.

O livro do professor da Universidade federal Rural do Rio de Janeiro José Nicolao Julião, intitulado Reflexões filosóficas sobre a história: Agostinho, Hegel e Nietzsche, publicado em 2019 pela editora Via Verita, é constituido de três "ensaios independentes, mas com um núcleo teórico comum: a reflexão filosófica sobre a história" (2019, p. 11). Como ressalta o próprio autor, o livro consiste em uma contribuição à disciplina academicamente estabelecida filosofia da história, todavia sem advogar em favor de uma teoria filosófica da história, mas buscando apresentar distintas interpretações filosóficas desta e, assim, ocupa-se com uma "visão panorâmica do grande percurso abarcado pela reflexão filosófica sobre a história" (2019, p. 11). Por conseguinte, é com essa perspectiva que o autor mobiliza três filósofos com perspectivas significativamente distintas, Agostinho, Hegel e Nietzsche. Muito embora Hegel, como ressalta o próprio autor, seja o único a formular uma teoria filosófica da história propriamente dita. A consideração dos três filósofos é então concebida pelo autor a partir de ênfases especificas: "Em Agostinho à história pensada como salvação, em Hegel, ao caráter especulativo e consequentemente sistemático da história e, em Nietzsche, por fim, a ideia de uma filosofia histórica criativa, que rompe drasticamente com os modelos de reflexão sobre a história" (2019, p. 12). Ter em vista essas caracteristicas é importante para compreender o objetivo do livro, qual seja, apresentar três diferentes reflexões filosóficas sobre a história não no sentido de conferir-lhes unidade de problematização, mas exatamente o contrário, evidenciar os aspectos que as especificam e as suas nuances próprias, para assim ressaltar a amplitude filosófica na consideração do tema. O volume é então composto por uma introdução seguida de três ensaios, cada um relativo a cada autor. Na ampla introdução há uma consideração bastante esclarecedora no que concerne à diferenciação 
das perspectivas dos filósofos e que pressupõe uma diferenciação dos três direcionamentos, a saber: a) A filosofia da história teológica (ou providencial); b) A filosofia da histórica metafísica ou especulativa; e c), a teoria da história surgida no contexto da filosofia alemã da primeira metade do século XIX, conjuntamente com a filosofia crítica da história, com a epistemologia desta, assim como a sua hermenêutica, mais especificamente nas escolas neokantianas, com o marxismo e com Nietzsche na virada daquele século (2019, p. 13). Segundo indicação do próprio autor, mesmo sem possuir uma seção específica acerca da teoria crítica da história, de cunho materialista e crítico à própria filosofia, o capítulo dedicado à reflexão de Nietzsche sobre a história foi pensado como uma forma de dissonância com respeito a este terceiro direcionamento, a partir da conjectura de que a crítica de Nietzsche à filosofia pressuposta no seu tratamento da historiografia não deixa de assimilar pressupostos ontológicos e transcendentais das filosofias de Kant e de Hegel (2019. p. 15). A indicação dessa problematização se justifica pela diferenciação - a partir do processo de concepção e de estabelecimento, a partir dos meados do século XIX - de uma ciência histórica em distanciamento tanto do idealismo, como de uma interpretação teleológica da história. O autor então considera o século XIX como o século da história, por conseguinte como o século do avanço das ciências históricas, em detrimento às interpretações filosóficas da história e identifica Nietzsche como uma variante filosófica desta tendência, que é um dos pontos de análise do capitulo dedicado as suas reflexões.

Mediante estas observações, a exposição é iniciada com um capítulo, dividido em três tópicos relativos à interpretação do tempo e da história por Agostinho. O material considerado é de seções especificas de duas obras, As confissões e $A$ cidade de Deus, a partir das quais, Julião aborda a interpretação da história feita pelo religioso cristão enquanto história da salvação e pautada em uma interpretação de tempo como continuidade linear, progressiva e determinada a partir da origem, por conseguinte da criação originária de todas as coisas pela divindade judaico-cristã. Especificado o ponto de partida da argumentação, ela tem início com a seção XI das confissões, a qual trata do conceito de tempo enquanto sucessão interna na alma em sua relação com a eternidade, que então é associada com a ideia de tempo linear, progressivo; fio condutor da história humana projetado nos livros XI e XXII de A cidade de Deus (2019, p. 35). A distinção feita na obra entre duas cidades, a divina (cidade de Deus) e a humana (cidade dos homens), pressupõe uma interpretação teleológica e progressiva do tempo, entendido como história progressiva da salvação. O primeiro tópico do capítulo, intitulado "Compreensão linear e tensa do tempo e o progresso histórico da salvação", reafirma o pressuposto argumentativo de Julião de aproximar as duas obras - e, por conseguinte, suas acepções de tempo e de história - a partir de sua aproximação tendo em vista o "processo de desenvolvimento da salvação" (2019, p. 43). Ressaltado é como Agostinho relaciona a descrição do processo interno de conversão, que pressupõe uma noção também interna de temporalidade, com uma interpretação da temporalidade da salvação que, todavia, é diferenciada da temporalidade histórica. Essas noções são mencionadas a fim de expor como o teólogo cristão interpreta a história como uma longa luta conta o mal e os seus periodos e épocas como etapas da história da salvação, pois para Agostinho não é possivel questionar a onisciência divina e, assim, é negada a possibilidade de um paralelismo entre as duas formas de percepção da temporalidade. Baseado nessa linha argumentativa, Julião evidencia a "teologia do Eu" com a ideia de linearidade progressiva do tempo, indicando a tensão entre as cidades enquanto dimensões de uma teologia da história, porém tomando o cuidado de ressaltar que "a compreensão linear do tempo [da salvação] não pode ser confundida com a ideia de tempo linear e cronológico" (2019, p. 45), pois o tempo da salvação não estaria submetido às mesmas contingências da temporalidade humana, mas vinculado ao processo gradual de luta contra o mal oriundo do mundo humano do livre-arbítrio 
na cidade terrena (2019, p. 72) até o juizo final e triunfo definitivo do bem sobre o mal (2019, p. 78).

A cidade de Deus é então o objeto da segunda seção do capítulo, na qual Julião continua a acentuar as correlações entre as duas obras de Agostinho a partir vetor teórico da história e ainda sob as indicações da impossibilidade de se confundir a história da salvação com a história secular. Esse aspecto é indicado como decisivo para que seja compreendida a classificação dos periodos históricos feita pelo religioso, que tem por fim explicitar aspectos da sua interpretação da história da salvação (2019, p. 69) e, portanto, da diferenciação de sua perspectiva de uma filosofia da história essencialmente teórica. O tópico então tematiza a tensão entre as duas cidades, subordinando a história à convicção religiosa, que "pressupõe uma realização gradual da história em uma longa luta contra o mal oriundo da cidade terrena" (2019, p. 72), pois a história, em sua complexidade, peripécias e vicissitudes no tempo, só pode ser plenamente compreendida pela divindade. Esses aspectos levam o autor a concluir que em A cidade de Deus, Agostinho efetivamente apresenta não uma teoria, mas uma teologia da história (2019, p. 81), ressaltando que, mesmo baseada em uma teleologia da salvação, ela exerceu importante influência sobre reflexões posteriores sobre o tema até a modernidade, quando, mesmo partindo da atividade interpretativa do sujeito racional, o pressuposto de uma teleologia da história foi mantido.

\section{Segundo ensaio: "A filosofia da História especulativa no sistema hegeliano da ciência"}

A partir do pressuposto segundo o qual a filosofia de Hegel é aquela na qual propositalmente é realizada uma filosofia da história, tendo como pressupostos uma interpretação da história mundial (Weltgeschichte) entendida como processo dotado de sentido racional, Julião enfaticamente indica, imediatamente nas linhas iniciais do resumo que, em Hegel "a história é elevada a um estatuto filosófico fundamental" (2019, p. 89). A argumentação que se segue busca evidenciar que a pressuposta teleologia racional do processo histórico concebida pelo filósofo alemão é o núcleo central da sua reflexão acerca da liberdade enquanto conceito fundamental. Nesse sentido, 0 autor firma acerca da filosofia hegeliana: "Filosofia é história e a história é a filosofia, no sentido de uma Weltgeschichte, compreendida como progresso da consciência como liberdade" (2019, p. 92). Os desdobramentos argumentativos que se seguem buscam tomar por base o pressuposto segundo o qual a história é interpretada por Hegel como "teleologia imanente do Espírito" (2019, p. 95) no progresso de consciência da liberdade entendida racionalmente. A reflexão sobre a história é assim indicada como núcleo do sistema filosófico hegeliano, objeto de análise da primeira seção do capítulo, intitulado "O Sistema da Ciência". Nela, Julião evidencia a associação da noção de Sistema com a interpretação histórica de Hegel, a partir da ideia de totalidade, considerada enquanto dinâmica e infinitamente progressiva (2019, p. 95). Esse pressuposto é indicado como nuclear para a compreensão da "ciência filosófica" hegeliana, de forte apelo imanentista, e imprescindivel à compreensão da tripartição da sua filosofia em lógica, filosofia da natureza e filosofia do espírito (2019, p. 98). Essas são objetos de análise na segunda seção, intitulada "O estatuto lógico-ontológico do conceito de liberdade na ciência da Lógica", na qual "a investigação filosófica da realidade é demonstrada como depende da representação fundante da lógica" (2019, p. 100) e pensada segundo o viés da reflexão histórica. Em sua argumentação, Julião busca mostrar que o conceito, enquanto representação fundamental, apreendido da coisa mesma (2019, p. 100), tem o seu processo de produção explicitado pela ciência da lógica, que se ocupa abstratamente com os argumentos e inferências válidas do pensamento. Para apresentar o conceito não apenas no seu caráter de representatividade, o autor indica a centralidade da progressividade relacionada à temporalidade e que para ele leva, na filosofia de Hegel, à ideia do absoluto enquanto manifestação da própria lógica, entendida como "exposição 
deste movimento de progressiva identificação entre representação e efetivação do absoluto enquanto ideia" (2019, p. 101).

Tal estratégia argumentativa se justifica e confirma na terceira seção, a qual se volta para a análise do caráter sistemático da história na filosofia de Hegel e, decisivamente, a partir da filosofia do direito. Nesta, a temporalidade é indicada como pressuposto interpretativo do movimento de superação da singularidade alienada da totalidade e da efetivação do Espírito objetivo no Estado. A história universal é apresentada como o pano de fundo no qual a efetivação do Espirito absoluto se dá e oferece compreensão e unidade às três disciplinas independentes que constituem o Espírito absoluto, a saber, a arte, a religião e a filosofia, pois ela é a "teleologia imanente do Espírito" (2019, p. 110) e a "expressão máxima do Espírito objetivo, ou seja, história da efetivação da liberdade no âmbito do Estado, legitimada pelo direito" (2019, p. 110).

Esses aspectos estruturais do sistema são conectados de forma decisiva na terceira e última seção, que se ocupa com a interpretação de Hegel da história universal nas suas "Lições sobre a filosofia da história". A partir das anotações decorrentes das últimas preleções (Vorlesungen) de Hegel enquanto professor da Universidade de Berlim, Julião busca especificar a concepção hegeliana de uma história universal filosófica, pressuposta enquanto "busca [por] contemplar a história na medida em que [esta] representa o governo da razão no mundo" (2019, 115). Sob o ponto de vista argumentativo, corroborado pelo dado cronológico do material das "Vorlesungen", a análise desse conteúdo é coerente e muito bem concatenada com as seções anteriores. Ela explicita o pressuposto teleológico-racional do tratamento filosófico dado por Hegel à história e, por conseguinte ao seu conceito de liberdade, unificando de forma conclusiva a exposição das seções anteriores. Desse modo, a análise da estrutura argumentativa das Preleções é apresentada de forma bastante competente e a interpretação de Hegel do percurso da história mundial a partir dos pressupostos da efetivação do Espírito absoluto e da liberdade evidenciam a centralidade da reflexão sobre a história em sua filosofia (2019, p. 170).

\section{Terceiro ensaio: "A história filosófica em Nietzsche: a história criativa"}

A terceira e conclusiva seção do livro, voltada à análise da consideração de Nietzsche sobre a história, articula ainda uma segunda pretensão. A de relacionar a reflexão do filósofo alemão com o contexto da crise da filosofia idealista e de ascensão das ciências particulares no século XIX, isso decisivamente no que se refere às ciências do "espirito". Partindo desse pano de fundo, Julião articula a reflexão acerca da história em Nietzsche com uma reconsideração da cultura e do humanismo no final do século XIX, tematizando noções como "consciência histórica, Historie, Geschichte, historicismo, espirito histórico e, ainda, civilização, Kulture Bildung" (2019, p. 149). No desenvolvimento argumentativo do tópico essa nova problematização deve também servir de base de compreensão da triade "sentido histórico, niilismo, genealogia" presente nuclearmente na obra do filósofo.

A abordagem segue uma linha cronológica dos escritos de Nietzsche. A primeira seção do capitulo, intitulada "A consideração de Nietzsche sobre o sentido histórico nos textos juvenis", trata desta noção que, para o autor, não é um conceito, mas que mediante ressignificações ocupa significação central na sua tematização da história (2019, p. 150). A argumentação explora a problematização do sentido histórico associada ao problema da cultura como aspecto decisivo na ruptura de Nietzsche com as noções de filosofia da história e história universal, compreendidas como advindas da metafísica e do idealismo. A indisposição com essas duas tendências é interpretada por Julião a partir da tensão no sistema educacional alemão no periodo (2019, p. 154), e que teria levado Nietzsche não apenas a aproximar-se da perspectiva científica em ascensão à época, mas também a divergir dela, o que se manifestaria na sua interpretação criativa da história a partir das influências artísticas (2019, p. 155).

O contexto da reflexão de Nietzsche sobre o sentido histórico é, portanto, o tema da segunda 
seção do capítulo, intitulado "O contexto crítico da segunda extemporânea". Essa se inicia com a indicação de que a problematização do sentido histórico não negligencia a história, mas se volta para uma crítica da cultura histórica.

O terceiro tópico continua a considerar a segunda das quatro considerações extemporâneas escritas por Nietzsche na década de 1870, intitulada Das vantagens e desvantagens da História para a vida e analisa a reflexão acerca da "cultura histórica" no contexto da crítica da "história da cultura racional" e do "predomínio dos interesses teóricos sobre quaisquer outros" (2019, p. 164). A partir desses pressupostos são evidenciados os aspectos que levam o filósofo alemão a descreditar a possibilidade de uma recuperação da história por vias racionalistas e, assim, a criticar a estagnação do saber histórico, da qual teria resultado um saber "historiográfico, instrutivo, enciclopédico e nostálgico" (2019, p. 164). Acrítica do sentido histórico, sob uma perspectiva que associa uma perspectiva médica com outra, a cultural - de onde decorre a ideia de um "médico da cultura" - problematiza a significação vital-cultural da ocupação com a história em Nietzsche e é compreendida por Julião como o momento na história do pensamento ocidental, no qual "a historiografia se volta contra si mesma" (2019, p. 168). Desse modo é conferido um significado histórico à reflexão de Nietzsche sobre a história, sob o ponto de vista de que com ela estaria indicada a necessidade de uma consideração histórica (e cultural) da própria historiografia.

Em um sentido interno, no que se refere à filosofia de Nietzsche, a critica da historiografia, por ele interpretada como presa ao passado, pauta-se na interpretação de sua clausura na tentativa de explicação racional do passado e, por isso, de sua negligência para com o presente, perdendo assim força criadora (plástica), que é indicada por Julião como pressuposto para a compreensão das noções de Vontade de poder e do método genealógico (2019, p. 173). Nesse sentido a seção posterior, a IV, avança na análise da consideração do sentido histórico nos escritos subsequentes, publicados e não publicados, indicando as mudanças de interpretações e de posicionamentos concernentes a ela e um amadurecimento com respeito aos estudos históricos (177). Nessa seção, Julião apresenta a hipótese interpretativa de que no final dos escritos da assim chamada fase intermediária, a análise do sentido histórico se desdobra na problemática do niilismo, entendido enquanto desvalorização dos valores fundamentais da cultura ocidental (2019, p. 184) e que, pensado em sua significação psicológica e fisiológica, é interpretado como "esgotamento progressivo de todos os sentidos", ou ainda, como "o reino em expansão do esvaziamento de todos os sentidos" (2019, p. 186). Associando o niilismo ao tema da morte de Deus, entendida como desencadeamento da percepção da insustentabilidade dos valores metafísicos, Julião associa, então, o tema do sentido histórico ao pensamento do Eterno retorno e com o projeto de transvaloração dos valores (2019, p. 189), ressaltando com isso as potencialidades interpretativas que a problemática apresenta para a compreensão de noções nucleares do pensamento do filósofo. A partir destes pontos é diferenciada a interpretação de Nietzsche da tradicional história da filosofia (2019, p. 192) e por isso na terceira seção do tópico, "Excurso sobre o Niilismo na Nietzsche Forschung" apresenta uma muito informativa sintese da discussão sobre o tema a partir de intérpretes como Martin Heidegger, Wolfgang Müller-Lauter, Paul von Tongeren e Werner Stegmaier, dentre outros.

Seguindo a linha cronológica inicial, a seção $\mathrm{V}$, última do livro, retoma o tema do sentido histórico nos escritos da chamada última fase, período no qual, como menciona Julião, o filósofo buscou conferir unidade mais evidente a sua obra (2019, p. 197). A argumentação busca enfatizar a centralidade da problemática da moral no período, para então relacionar a reflexão histórica como desempenhando um papel importante na relativização dos valores, em oposição à concepção metafísica da atemporalidade dos mesmos (2019, p. 197). A hipótese hermenêutica da abordagem é a de que a critica do historicismo, concomitantemente a valorizações da perspectiva histórica 
não pautada em uma crença na possibilidade de compreensão determinante do passado, é o fator decisivo com o qual Nietzsche desenvolve a sua genealogia (2019, p. 199). Esta compreendida enquanto forma de compreensão de como "os valores morais emergiram, se transformaram e até mesmo se dissolveram sob outras condições de existência" (2019, p. 200). Em subseções seguintes são analisados os usos de perspectivas históricas da análise nas obras de última fase, mais especificamente Além de bem e mal e Para a genealogia da Moral. Nas quais o autor busca demonstrar a viabilidade da hipótese de que a reflexão histórica de Nietzsche constitui o pano de fundo do uso do método genealógico referente à interpretação e crítica dos valores da cultura ocidental no horizonte do niilismo denunciado pelo filósofo (2019, p. 211). Nas páginas finais deste último tópico são evidenciados os aspectos criticos do Nietzsche entende como o uso da história em sua análise genealógica, o que o distancia da visão ampla e simplificada que a recepção do evolucionismo darwinista adquiriu em seu tempo, mas também de pressupostos epistemológicos da historiografia associada à plausibilidade de uma interpretação objetiva, neutra e com sentido natural da história. Coerentemente, Julião tende a considerar a posição de Nietzsche como uma espécie de "teoria antirrealista da interpretação" (2019, p. 214), que, portanto, se afasta de pressupostos das interpretações da filosofia da histórica, tais como "causa", "efeito", "causalidade". Desse modo, é indicada a interpretação histórica como "funções no mundo histórico" e, finalmente, apartada de qualquer perspectiva não interpretativa da mesma (2019, p. 215).

\section{Considerações finais}

O livro de José Nicolao Julião, muito embora as diferenças de problematização e perspectivas entre os autores que analisa, mantém, em seu conjunto, uma unidade, mesmo que nesta a reflexão de Nietzsche seja indicada como ponto de divergência aos posicionamentos de Agostinho e de Hegel. Eventualmente, o texto poderia ter explorado de modo mais detido os pontos de rup- tura com que Nietzsche visou, decisivamente, no que diz respeito à proveniência religiosa da noção da teleologia histórica. Todavia, no viés de análise desta perspectiva ele oferece interessantes e bem justificadas leituras dos autores considerados, dentro de sua proposta de oferecer uma visão panorâmica e temporalmente ordenada das reflexões filosóficas sobre a história e desse modo, consiste em um importante material de referência com respeito à multiplicidade de considerações e perspectivas filosóficas acerca da história.

\section{Roberto Barros}

Doutor pela Universidade Técnica de Berlim (TU-Berlin), em Berlim, Alemanha; mestre em Filosofia pela Universidade estadual de Campinas (UNICAMP), em Campinas, SP, professor do departamento de filosofia e do PPGFIL da Universidade Federal do Pará (UFPA), em Belém, PA, Brasil.

\section{Endereço para correspondência}

Universidade Federal do Pará

Instituto de Filosofia e Ciências humanas

Faculdade de Filosofia

Rua Augusto Correia, 1

Guamá, 660075-111

Belém, PA, Brasil

Os textos deste artigo foram revisados pela Poá Comunicação e submetidos para validação do autor antes da publicação. 